\title{
SMART: инновационная концепция фармакотерапии персистирующей бронхиальной астмы
}

Государственный институт усовершенствования врачей Министерства обороны Российской Федерации: 107392, Москва, ул. Малая Черкизовская, 7

\section{T.A.Bikmasova, I.L.Klyachkina \\ SMART: innovative concept of pharmacotherapy of persisting asthma}

\section{Summary}

The aim of this study was evaluation of efficacy and safety of the SMART strategy with formoterol / budesonide (Symbicort, AstraZeneca, Sweden) for maintenance and relief therapy of poorly controlled asthma. The study involved 118 patients with poorly controlled asthma (56 males, 62 females) aged 41 to 88 years with the need in inhaled short-acting $\beta_{2}$-agonist (SABA) to relieve daytime and nighttime asthma symptoms and $\geq 1$ acute exacerbation of the disease in the previous year. After 2-week run-in period, the $1^{\text {st }}$ group patients $(n=26)$ was administered formoterol / budesonide $4.5 / 160 \mu \mathrm{g}$ one inhalation b.i.d.; they were also permitted up to 10 additional inhalations per day to relieve asthma symptoms. The $2^{\text {nd }}$ group patients $(n=36)$ received formoterol / budesonide $4.5 / 160 \mu \mathrm{g}$ two inhalations b. i. d. and up to 8 additional inhalation per day as-needed. The $3^{\text {rd }}$ group patients $(n=42)$ received low to moderate doses of ICS (up to $1000 \mu \mathrm{g}$ of beclomethasone equivalent daily) and the $4^{\text {th }}$ group patients were treated with high doses of ICS ( 1000 to $2000 \mu \mathrm{g}$ of beclomethasone equivalent daily) in combination with the long-acting $\beta_{2}$-agonist formoterol plus inhalations of SABA as-needed. The results were assessed in 12 and 24 weeks of the treatment. Patients received formoterol / budesonide for maintenance and relief therapy (the $1^{\text {st }}$ and the $2^{\text {nd }}$ groups) showed 1.7 -fold and 4.3 -fold decrease in daytime asthma symptoms, respectively; 2.7 -fold and 6-fold decrease in nighttime asthma symptoms, respectively; 1.8-fold and 4.4-fold decrease in the need in SABA, respectively; and 1.3-fold and 1.2 -fold increase in $\mathrm{FEV}_{1}$, respectively. Asthma control according to the ACT test improved 1.5 times and 1.6 times, respectively. Easy to use and convenience were additional benefits of the SMART strategy which implies a single inhalator for maintenance and relief therapy. Key words: bronchial asthma, SMART strategy, formoterol / budesonide.

\section{Резюме}

Целью проведенного исследования являлась оценка эффективности и безопасности стратегии SMART (применение формотерола / будесонида (Симбикорт, Astra Zeneca, Швеция) для базисной и симптоматической терапии) при неконтролируемой бронхиальной астме (БА). В исследование были включены 118 пациентов с неконтролируемой БА (56 мужчин и 62 женщины) в возрасте от 41 года до 88 лет, которые использовали ингаляции коротко действующего $\beta_{2}$-агониста (КДБА) по требованию для купирования дневных и ночных проявлений заболевания и имели $\geq 1$ обострения заболевания в течение предшествующего года. После 2-недельного вводного периода 1-й группе $(n=26)$ пациентов назначался формотерол / будесонид 4,5 / 160 мкг по 1 ингаляции 2 раза в день регулярно (дополнительно допускалось до 10 ингаляций для купирования симптомов БА). Пациентам 2-й группы $(n=36)$ назначался формотерол / будесонид 4,5 / 160 мкг по 2 ингаляции 2 раза в день регулярно (дополнительно допускалось до 8 ингаляций в сутки). Пациенты 3 -й группы ( $n=42)$ получали низкие / средние дозы иГКС (до 1000 мкг в сутки в перерасчете на беклометазон), а пациенты 4-й группы ( $n=14)-$ высокие дозы иГКС (от 1000 до 2000 мкг в сутки в перерасчете на беклометазон) в сочетании с длительно действующим $\beta_{2}$-агонистом формотеролом и ингаляции КДБА по требованию для купирования симптомов. Оценка состояния пациентов проводилась через 12 и 24 нед. терапии. На фоне применения формотерола / будесонида для базисной и симптоматической терапии БА у пациентов 1-й и 2-й лечебных групп уменьшились дневные (в 1,7 и 4,3 раза соответственно) и ночные (в 2,7 и 6 раз соответственно) симптомы заболевания. Применение формотерола / будесонида сопровождалось снижением необходимости в КДБА "по требованию" в 1-й и 2-й лечебной группе (в 1,8 и в 4,4 раза соответственно). Было отмечено достоверное увеличение объема форсированного выдоха за 1-ю с в 1-й и 2-й группе (в 1,3 и 1,2 раза соответственно). В указанных группах повысился уровень контроля БА по результатам теста АСТ (в 1,5 и 1,6 раза соответственно). Дополнительным преимуществом использования стратегии SMART являлись простота и удобство использования 1 ингалятора больными БА как для проведения базисной терапии, так и для купирования симптомов заболевания.

Ключевые слова: бронхиальная астма, стратегия SMART, формотерол / будесонид.

Бронхиальная астма (БА) является глобальной медицинской проблемой: в мире 300 млн больных. Распространенность БА в разных странах мира колеблется от 1 до $18 \%$ [1]. В России официально зарегистрировано около 1 млн человек с диагнозом БА, а согласно результатам выборочных эпидемиологических исследований, это число приближается к 7 млн [1-3]. Несмотря на успехи, достигнутые в лечении данного заболевания, контроль над его течением остается недостаточным. По данным эпидемиологических исследований, БА полностью контролируется у $<5 \%$ пациентов [1]. Неконтролируемая БА представляет собой значительную медико-социальную проблему - прежде всего, из-за относительно высокой смертности среди этой категории больных [1,
4]. Актуальными являются также социально-экономические аспекты неконтролируемой БА, обусловленные как прямыми, медицинскими, затратами (стоимость госпитализаций и лекарственных препаратов), так и непрямыми, немедицинскими (дни нетрудоспособности, преждевременная смерть) [1]. Повышение эффективности терапии этого заболевания является одной из важнейших задач. Постоянно продолжается поиск новых эффективных медикаментозных средств и режимов их дозирования, совершенствуются средства доставки противоастматических препаратов.

Современная концепция патогенеза БА основана на развитии аллергического воспаления в стенке бронхов, в формировании которого принимают 
участие тучные клетки, эозинофилы, Т-лимфоциты и др. Поэтому наиболее важны в терапии пациентов с БА препараты, влияющие на воспалительный процесс, - глюкокортикостероиды, как ингаляционные (иГКС), так и системные (сГКС).

Задачей лечения больных БА в настоящее время является эффективный контроль заболевания [1]. В современных руководствах рекомендуется использовать $\beta_{2}$-агонисты длительного действия при недостаточном контроле БА монотерапией иГКС. Комбинация иГКС / длительнодействующий $\beta_{2}$-агонист (ДДБА) более эффективна, чем удвоение дозы иГКС и приводит к более значимому улучшению функции легких и лучшему контролю над симптомами БА, снижению количества обострений, повышению качества жизни пациентов [1]. Данные клинических исследований подтверждают высокую эффективность и значительные экономические преимущества комбинированной терапии [4-6].

Под влиянием различных факторов (аллергенов, вирусов, поллютантов) могут формироваться разные варианты БА, в связи с чем для каждого больного необходимо подбирать индивидуальные дозы препаратов в зависимости от изменения течения патологии. Задача врача - добиться максимального клинического эффекта, используя минимальное количество лекарственных средств.

Зарекомендовавшим себя подходом к терапии БА является концепция SMART (Symbicort Maintenance and Reliever Therapy - базисная и симптоматическая терапия с использованием формотерола / будесонида (Симбикорта)). Она предполагает использование фиксированной комбинации формотерола / будесонида как в качестве средства постоянной базисной терапии БА (по 1 или 2 ингаляции утром и вечером), так и по потребности - для купирования симптомов заболевания, вместо ингаляций короткодействующих $\beta_{2}$-агонистов (КДБА). Такой режим (лечение 1 ингалятором), несомненно, удобен для больных. Кроме того, применяя формотерол / будесонид для купирования симптомов, пациенты при ухудшениях состояния и появлении потребности в дополнительных ингаляциях наряду с бронхолитиком (формотеролом) одновременно получают дополнительную дозу противовоспалительного иГКС. Это позволяет непосредственно увеличивать объем противовоспалительной терапии уже в первые часы при ухудшении самочувствия и предотвращать развитие обострения БА на ранней стадии [7]. К тому же при данной стратегии дозирования формотерол / будесонид используется в оптимальной дозе, соответствующей состоянию больного, что уменьшает суммарную дозу иГКС.

Эффективность SMART была доказана в ходе 9 крупных международных рандомизированных исследований с участием 26900 больных. Было показано, что использование этой стратегии обеспечивает лучшую профилактику обострений и высокую степень контроля над БА. На основании данных работ применение SMART было одобрено в Глобальной инициативе по бронхиальной астме (GINA) в 2006 г.
Цель настоящего исследования - оценить эффективность и безопасность стратегии SMART применения формотерола / будесонида (Симбикорта, AstraZeneca) для базисной и симптоматической терапии - при неконтролируемой БА.

\section{Материалы и методы}

В исследовании участвовали 118 пациентов - 56 мужчин $(47,46 \%)$ и 62 женщины $(52,54 \%)$ в возрасте от 41 до 88 лет (средний возраст - 64,4 \pm 9,4 года). Средняя продолжительность заболевания составила $28,50 \pm 6,66$ года. В течение предшествующего года 60 пациентов $(50,84 \%)$ из числа включенных в исследование перенесли 1 обострение БА, в т. ч. 26 пациентов $(43,3$ \%) - тяжелое, потребовавшее назначения сГКС, из них 20 больных (33,3 \%) были госпитализированы. Все без исключения пациенты до включения в исследование получали комбинацию иГКС / ДДБА. У всех 118 больных (100 \%) БА была неконтролируемой, и они использовали КДБА по требованию, что являлось условием включения в исследование. По статусу курения бывшими курильщиками со стажем < 10 пачек / лет оказались 22 пациента (18,64 \%), остальные были некурящими.

После 2-недельного вводного периода (рис. 1) на 2-м визите все пациенты случайным образом были распределены по 2 группам в зависимости от применения конкретной терапии: группа SMART (формотерол / будесонид) и группа обычной терапии (OT). Эти группы не различались по полу, возрасту, продолжительности симптомов БА и терапии (табл. 1).

По клиническим и функциональным характеристикам достоверных различий между группами также не было, что учитывалось при последующем анализе эффективности терапии (табл. 2).

Лечебный период составил 24 нед. (рис. 1). Оценка состояния пациентов проводилась через 12 нед. (3-й визит) и 24 нед. (4-й визит).

В группу SMART вошли 62 больных, в группу OT - 56. Пациенты, получающие терапию по стратегии SMART, слепым методом были распределены в 2 группы в зависимости от поддерживающей дозы препарата. 1-й группе $(n=26)$ назначался формотерол / будесонид 4,5 / 160 мкг по 1 ингаляции дважды в день регулярно, и дополнительно допускалось до 10 ингаляций для купирования симптомов. Во 2-й

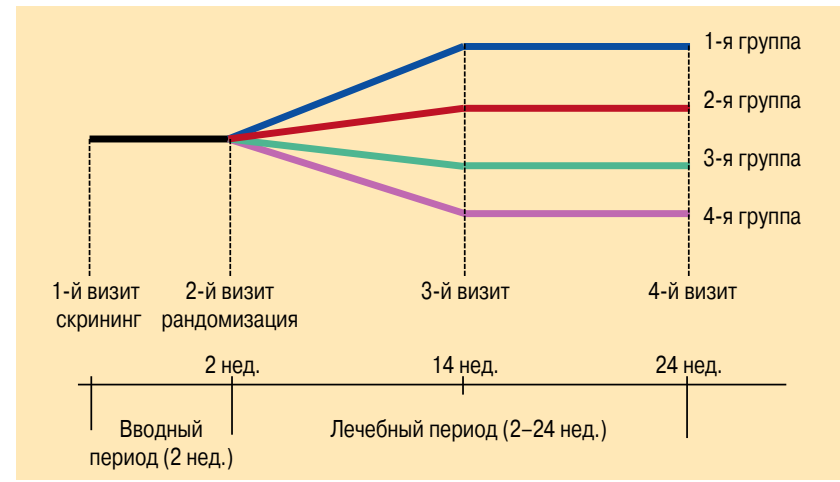

Рис. 1. Дизайн исследования 
Таблица 1

Общая характеристика пациентов, включенных в исследование

\begin{tabular}{|c|c|c|c|}
\hline Параметр & Группы SMART (1-я и 2-я), n= 62 & Группы контроля (3-я и 4-я), $n=56$ & $p$ \\
\hline Пол & & & 0,855 \\
\hline $\mathrm{M}, n(\%)$ & $30(48,39)$ & $26(46,43)$ & \\
\hline ж, $n(\%)$ & $32(51,61)$ & $30(53,57)$ & \\
\hline Возраст, лет & $64,10 \pm 10,38$ & $64,90 \pm 8,26$ & 0,649 \\
\hline Продолжительность БА, лет & $27,80 \pm 6,22$ & $29,32 \pm 7,08$ & 1,0 \\
\hline Статус курения & & & 0,83 \\
\hline никогда не курили, $n$ (\%) & $50(80,65)$ & $46(19,35)$ & \\
\hline бывшие курильщики, $n$ (\%) & $12(82,14)$ & $10(17,86)$ & \\
\hline Терапия БА до включения в исследование & & & NS \\
\hline иГКС / ДДБА в виде свободной комбинации, $n$ (\%) & $30(48,38)$ & $56(100)$ & \\
\hline иГКС / ДДБА в виде фиксированной комбинации, $n$ (\%) & $32(51,61)$ & & \\
\hline ингаляционные КДБА, $n$ (\%) & $62(100)$ & $56(100)$ & \\
\hline
\end{tabular}

Примечание: NS - различия недостоверны.

группе $(n=36)$ применяли формотерол / будесонид 4,5 / 160 мкг по 2 ингаляции дважды в день регулярно, и дополнительно допускалось до 8 ингаляций в сутки. Таким образом, максимальное количество ингаляций формотерола / будесонида 4,5 / 160 мкг в сутки должно было составить не более 12 . Все другие препараты, которые ранее принимали больные, при включении в исследование отменялись.

Пациенты группы ОТ продолжали лечиться так же, как и до участия в исследовании: свободными комбинациями различных иГКС с ДДБА (формотеролом) и ингаляциями КДБА по требованию для купирования симптомов. В зависимости от доз иГКС больные, получавшие ОТ, были разделены на 2 группы: пациенты 3 -й контрольной группы $(n=42)$ принимали низкие и средние дозы иГКС $(<1000$ мг в перерасчете на беклометазон), а пациенты 4-й контрольной группы $(n=14)$ - высокие дозы иГКС (> 1000 мкг в перерасчете на беклометазон).

Диагноз БА устанавливался с учетом данных опроса и объективного обследования пациентов и соответствовал критериям GINA.

Состояние пациентов (оценка жалоб, измерение уровня артериального давления (АД), частоты сердечных сокращений (ЧСС), физикальное обследование) оценивалось во время визитов (рис. 1). Кроме того, больные ежедневно вели дневники самонаблюдения, в которые вносили результаты утреннего и вечернего значения пиковой скорости выдоха (ПСВ) до ингаляции бронхолитических препаратов, значе- ния АД, ЧСС. Пациенты также отмечали изменения в своем самочувствии. Безопасность исследуемой терапии оценивали по динамике электрокардиографического исследования и регистрации нежелательных явлений в дневниках самонаблюдений. Об эффективности лечения судили по изменению бронхиальной проходимости (данные аускультации, пикфлоуметрии, спирографии). Исследование функции внешнего дыхания (ФВД) проводилось через 2 нед. вводного периода, затем - через 12 и 24 нед. терапии. Определялись следующие показатели: форсированная жизненная емкость легких (ФЖЕЛ), объем форсированного выдоха за 1-ю с $\left(\mathrm{OФB}_{1}\right)$, отношение ОФВ 1 ФЖЕЛ, средняя объемная скорость в интервале между 25 и 75 \% ФЖЕЛ $\left(\mathrm{COC}_{25-75}\right)$, максимальные объемные скорости потоков после выдоха 25, 50 и $75 \%$ ФЖЕЛ (MOC $\left.25, \mathrm{MOC}_{50}, \mathrm{MOC}_{75}\right)$. Показатели рассчитывались в \%дол.. В ходе спирометрии оценивалась обратимость бронхиальной обструкции в ответ на ингаляцию 400 мкг сальбутамола. Оценка клинической эффективности терапии осуществлялась по таким параметрам, как частота дневных и ночных симптомов БА по 5-балльной шкале симптомов, частота ингаляций по требованию формотерола / будесонида в группах SMART и КДБА - в группах ОТ. Оценка контроля над симптомами БА осуществлялась по результатам теста по контролю над астмой (АСТ $\left.{ }^{\mathrm{TM}}\right)$. Результат оценивался в баллах от 1 до 25: 25 баллов - полный контроль над симптомами БА, 20-24 балла - неполный, $\leq 19$ бал-

Таблица 2

Клиническая и функциональная характеристики пациентов до начала исследования

\begin{tabular}{|l|c|c|r|r|}
\multicolumn{1}{c|}{ Показатель } & 1-я группа, $n=26$ & 2 -я группа, $n=36$ & 3-я группа, $n=42$ & 4 -я группа, $n=14$ \\
\hline Возраст, лет & $60,20 \pm 8,54$ & $66,90 \pm 10,78$ & $64,00 \pm 8,42$ & $67,40 \pm 7,46$ \\
Предбронхолитический ОФВ ${ }_{1}, \pi$ & $1,770 \pm 0,662$ & $1,940 \pm 0,541$ & $1,880 \pm 0,364$ & $1,860 \pm 0,451$ \\
\hline ПСВ, л/мин & $219,40 \pm 76,06$ & $255,80 \pm 63,78$ & $222,50 \pm 56,78$ & $220,30 \pm 38,54$ \\
\hline Дневные симптомы, баллы & $1,810 \pm 0,110$ & $1,800 \pm 0,169$ & $1,810 \pm 0,156$ & $1,710 \pm 0,172$ \\
\hline Ночные симптомы, баллы & $0,300 \pm 0,047$ & $0,300 \pm 0,052$ & $0,300 \pm 0,065$ & $0,300 \pm 0,064$ \\
\hline $\begin{array}{l}\text { Прием препаратов по требованию } \\
\text { В течение суток, раз в сутки }\end{array}$ & $2,20 \pm 0,18$ & $2,20 \pm 0,18$ & $2,20 \pm 0,22$ & $2,20 \pm 0,16$ \\
\hline АСТ, баллы & $13,30 \pm 2,84$ & $12,40 \pm 3,67$ & $13,80 \pm 3,48$ & $11,70 \pm 4,10$ \\
\hline
\end{tabular}


лов - плохой контроль. Частоту и тяжесть обострений БА оценивали в течение всего периода лечения на основании дневников самонаблюдения по следующим показателям: увеличению выраженности клинической симптоматики, сопровождающемуся снижением показателей ОФВ 1 , ПСВ, изменением базисной терапии (прием ГКС перорально или парентерально); госпитализации в стационар; обращению за скорой медицинской помощью.

\section{Результаты и обсуждение}

\section{Оценка эффективности терапии}

По результатам проведенного исследования формотерол / будесонид для базисной и симптоматической терапии продемонстрировал высокую эффективность в терапии неконтролируемой БА. На фоне лечения этим препаратом существенно снизились частота и выраженность дневных проявлений БА (приступов удушья, одышки, затрудненного дыхания или кашля днем) в 1-й группе с 1,81 \pm 0,11 до $1,050 \pm 0,142$ балла $(p<0,01)$, а во 2-й группе c $1,800 \pm 0,169$ до $0,410 \pm 0,201$ балла $(p<0,01)$. В то же время у пациентов 3-й и 4-й групп, получающих ОТ, динамика дневных проявлений БА отсутствовала.

У больных, получающих формотерол / будесонид, также регистрировалось статистически значимое снижение ночных симптомов БА (приступов удушья, одышки, затрудненного дыхания или кашля ночью) с 0,300 $\pm 0,047$ до $0,110 \pm 0,101$ балла в 1 -й группе $(p<0,01)$ и с $0,300 \pm 0,052$ до $0,050 \pm 0,033$ балла - во 2-й $(p<0,01)$. В то же время в 3-й и 4-й группах контроля не было динамики частоты ночных проявлений БА.

Применение формотерола / будесонида для базисной и симптоматической терапии позволило существенно снизить частоту ингаляций по требованию с 2,20 \pm 0,18 до 1,20 \pm 0,27 ингаляции в сутки в 1-й группе $(p<0,01)$ и с 2,20 $\pm 0,18$ до 0,50 $\pm 0,18$ ингаляции в сутки - во 2 -й $(p<0,01)$. В контрольных группах пациенты использовали КДБА для купирования дневных и ночных проявлений БА в таком же количестве, как и до начала исследования (рис. 2).

Клиническое улучшение у пациентов групп SMART сопровождалось статистически значимым увеличением балльной оценки по результатам АCT с 13,30 $\pm 2,84$ до 20,20 $\pm 3,25$ балла в 1-й группе ( $p<$ $0,01)$ и с $12,40 \pm 3,67$ до 20,60 \pm 4,99 балла - во 2-й $(p<0,01)$, что позволяет сделать вывод об улучшении контроля БА. Напротив, у больных, получающих ОТ, контроль над БА существенно не улучшился, по результатам АСТ, за время участия в исследовании. Необходимо отметить, что в момент включения в исследование по результатам тестирования ни у одного пациента не было полного контроля над заболеванием, что соответствовало критериям включения в исследование. У всех пациентов групп SMART и OT исходно контроль над БА был плохим, т. е. сумма баллов по результатам теста составляла < 20. Через 12 нед. терапии неполный контроль регистрировался у 8 пациентов (30,8\%) 1-й

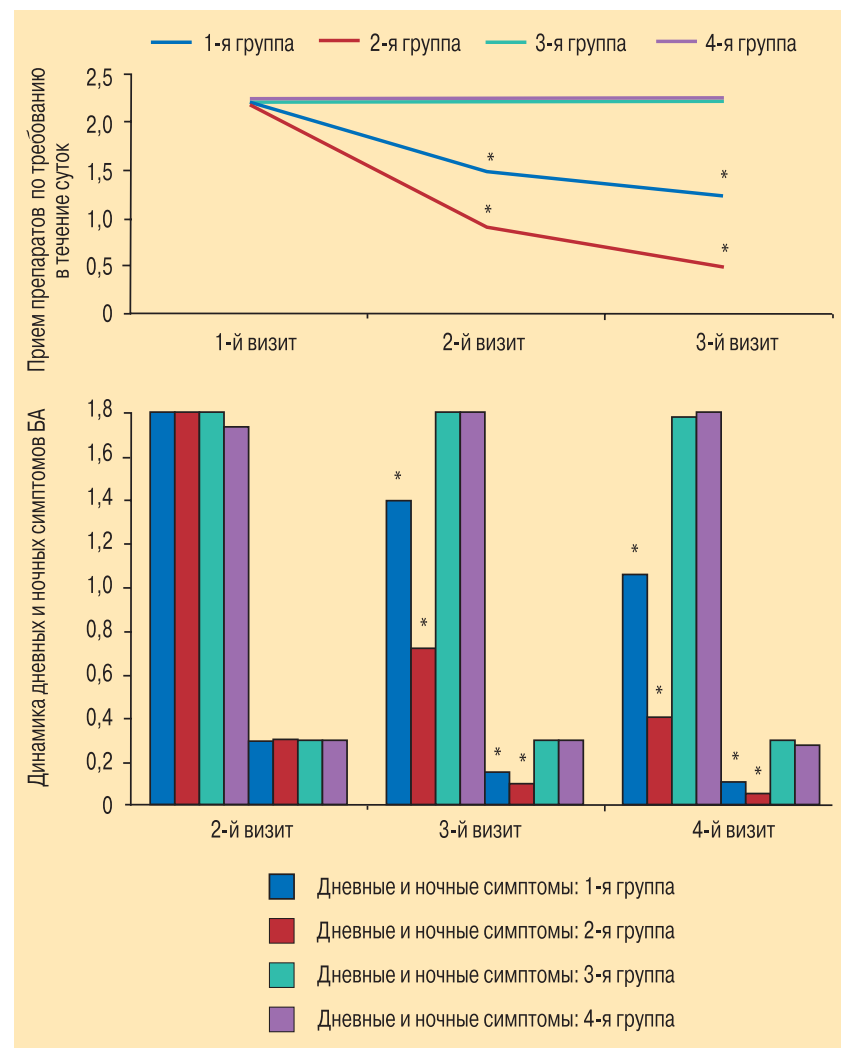

Рис. 2. Динамика дневных и ночных симптомов, необходимости в препаратах по требованию

Примечание: * $-p<0,05$ по сравнению со 2-м визитом.

группы и 8 (22,2 \%) - 2-й. Полного контроля достигли 4 человека $(15,4 \%)$ в 1-й группе и $8(22,2 \%)-$ во 2-й. В то же время в 3-й и 4-й группах у всех больных БА была неконтролируемой. Через 24 нед. терапии количество пациентов, имеющих неполный контроль, увеличилось до 10 (38,5 \%) в 1-й группе и до $12(33,3 \%)-$ во 2-й. Полного контроля достигли 4 больных (15,4 \%) в 1-й группе и 12 (33,3\%) - во 2-й. В контрольных группах только 3 пациента $(5,36 \%)$ достигли частичного контроля над БА после завершения исследования.

На фоне терапии формотеролом / будесонидом достоверно улучшились показатели ФВД. Так, выявлен статистически значимый прирост ОФВ 1 в 1-й группе с 1,770 $\pm 0,662$ до 2,320 $\pm 0,314$ л $(p<0,01)$ и во 2-й группе - с 1,940 \pm 0,541 до 2,500 $\pm 0,464$ л $(p<0,01)$. В 3-й и 4-й группах динамика данного показателя отсутствовала.

При анализе динамики утренней ПСВ выявлено ее статистически значимое повышение в 1-й группе с 219,40 $\pm 76,06$ до $304,10 \pm 30,02$ л/мин $(p<0,01)$ и с $255,80 \pm 63,78$ до $351,10 \pm 89,00$ л/мин $(p<0,01)-$ во 2-й. В 3-й и 4-й группах значимых изменений исследуемого показателя не регистрировалось.

На протяжении исследования обострения БА развились у 43 пациентов (36,4 \%). Падение показателя ПСВ $<70 \%$ от исходного среднего значения в течение $\geq 2$ дней подряд без повышения потребности в ингаляциях по требованию расценивалось как признак легкого обострения, было зарегистрировано только у 8 пациентов контрольных групп и не требовало изменения терапии. 
Увеличение частоты и тяжести клинических симптомов БА (приступов затрудненного дыхания, кашля или удушья в дневное и ночное время), сопровождавшееся снижением ПСВ и повышенной потребностью в дополнительных ингаляциях, указывало на среднетяжелое обострение. Оно возникало у 4 больных (15,3\%) 1-й группы и у 2 (5,6 \%) - 2-й группы. У пациентов, получающих ОТ, такое обострение развились в 10 случаях $(23,8 \%)$ в 3-й группе и в 4 случаях $(28,6 \%)$ - в 4-й.

Тяжелое обострение БА в 1-й группе наблюдались только у 1 пациентки с неконтролируемой БА. При включении в исследование она лечилась высокими дозами иГКС в сочетании с ДДБА. При ухудшении самочувствия она получала максимальное количество дополнительных ингаляций - 10 в сутки. Несмотря на это, у больной было 2 тяжелых обострения, потребовавших назначения пероральных ГКС. У 9 пациентов $(21,4$ \%) 3-й группы и у 5 (35,7 \%) 4-й группы в течение 6 мес. исследования возникали тяжелые обострения, потребовавшие госпитализации.

Таким образом, у пациентов, получающих формотерол / будесонид для базисной и симптоматической терапии, обострение развивались реже, чем у больных на ОТ.

\section{Оценка безопасности терапии}

Отрицательной динамики клинических показателей безопасности (АД, ЧСС, нарушения ритма сердца), а также достоверных изменений длительности интервала QT не было обнаружено ни в одной из групп.

За все время исследования нежелательные явления были зарегистрированы у 29 пациентов (24,58 \%). Осиплость голоса развивалась у 15 человек в группах SMART и у 13 - в группах OT. Такое нежелательно явление относилось к легкой степени тяжести и не требовало исключения из исследования. У 1 пациентки, принимающей формотерол / будесонид, был выявлен орофарингеальный кандидоз, и она была досрочно исключена из исследования. Таким образом, статистически значимые различия в безопасности формотерола / будесонида для базисной и симптоматической терапии и ОТ отсутствовали.

\section{Заключение}

Результаты исследования показывают, что применение формотерола / будесонида для базисной и симптоматической терапии неконтролируемой БА более эффективно улучшает функцию легких, статистически значимо уменьшает частоту дневных и ночных проявлений заболевания, сокращает потребность в дополнительных ингаляциях для купирования симптомов БА, чем обычная терапия иГКС, ДДБА и КДБА. При этом снижаются количество обострений БА и их тяжесть, улучшается уровень контроля над заболеванием. Дополнительным преимуществом этого метода является простота и удобство для больного, т. к. необходимо использовать только 1 ингалятор для базисной терапии и для купирования симптомов БА, что является важным аргументом повышения приверженности больных к лечению.

\section{Литература}

1. Global Initiative for Asthma (GINA). www.ginaasthma.org

2. Голевцова З.Ш., Багишева Н.В., Овсянников Н.В. Диагностическая ценность и информативность клинических и фенотипических признаков в ранней диагностике бронхиальной астмы. Пульмонология 2005; 1: 48-52.

3. Чучалин А.Г. Актуальные вопросы диагноза в пульмонологии. Пульмонология 2001; 1: 6-11.

4. Masoli M., Fabian D., Holt S., Beasley R. The global burden of asthma: executive summary of the GINA Dissemination Committee report. Allergy 2004; 59 (5): 469-783.

5. Lundback B., Price M.J., Thwaites R.N.A. et al. The costeffectiveness of salmeterol / fluticasone propionate combination product and budesonide in asthma. Eur. Respir. J. 1999; 14 (supp 1., 30): 370s.

6. Pieters W.R., Wilson K.K., Smoth H.S.E., Tammimga J.J. Cost-effectivness of fluticasone propionate / salmeterol combination product and fluticasone propionate / montelucast in asthma. Am. J. Respir. Crit. Care Med. 2001; 163 (5): A463.

7. Reddel H.K., Barnes D.J. Pharmacological strategies for self-management of asthma exacerbations. Eur. Respir. J. 2006; 28 (1): 182-199.

\section{Информация об авторах}

Бикмасова Татьяна Анатольевна - адъюнкт кафедры терапии ГИУВ МО РФ; тел.: (499) 263-53-74; e-mail: tanya-es-medica@mail.ru

Клячкина Ирина Львовна - к. м. н., доцент кафедры пульмонологии ГИУВ МО РФ; тел.: (499) 263-55-30; e-mail: formozailk@rambler.ru 


\section{Пульмикорт द. Суспензия иткс для небулайзерной терапии}

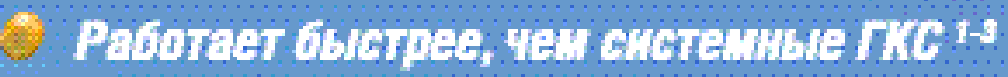

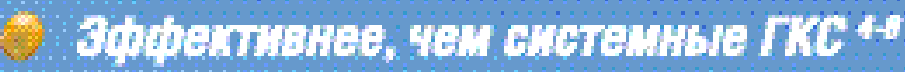

- Уиикапьный профиив безопвавновт"

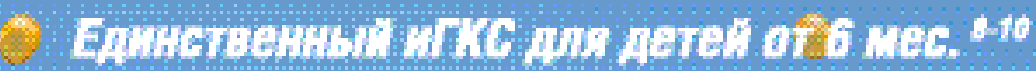

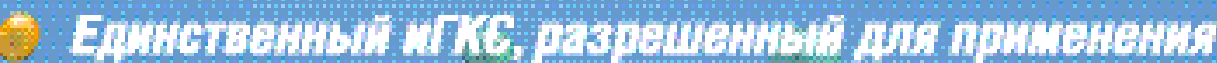

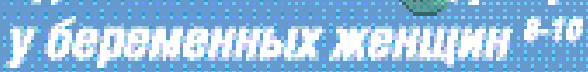

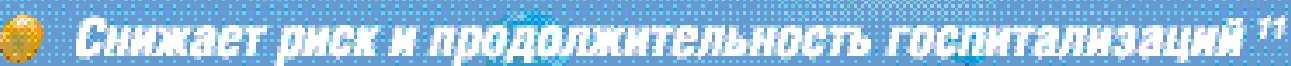

$\infty$

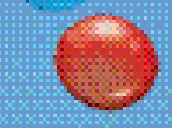

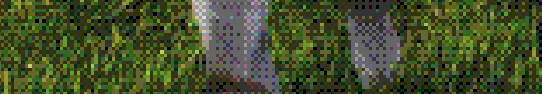

$1309 x^{2}=$
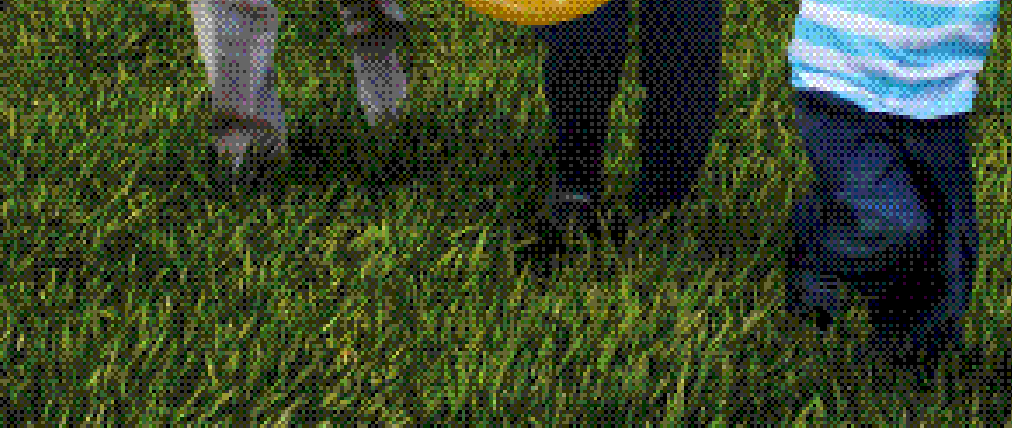

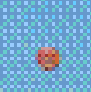
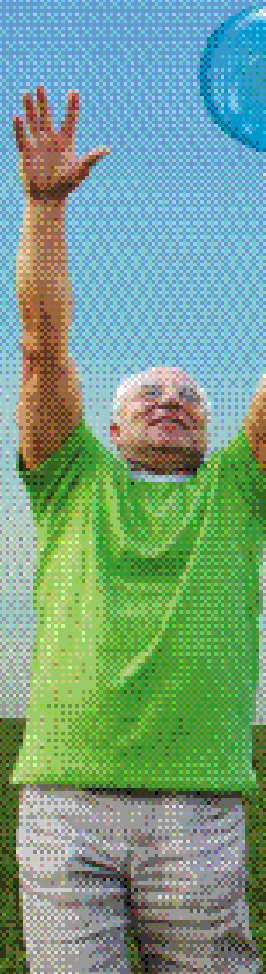

$+\frac{1}{2}+\frac{1}{2}$

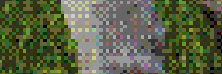

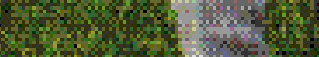

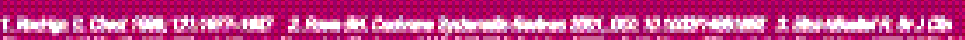

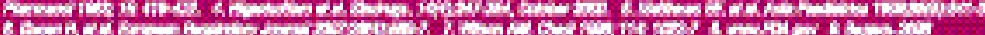

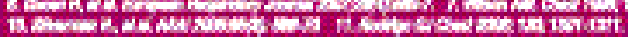

Астразенека $\%$

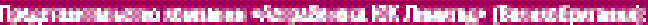

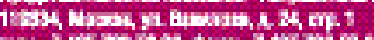

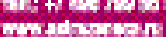

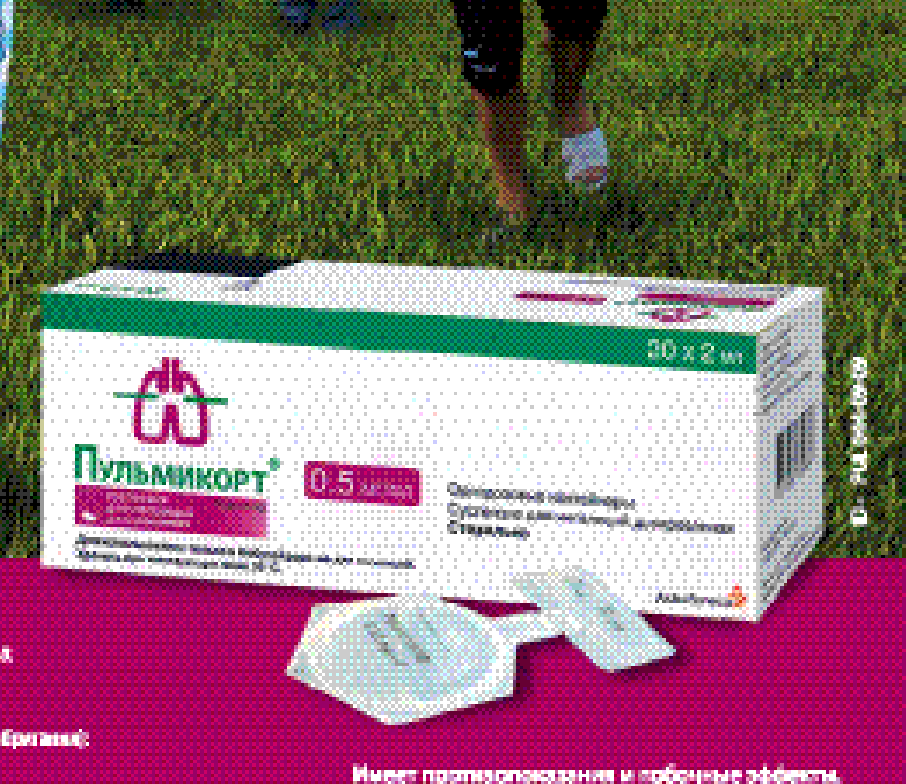

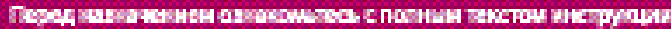

